\title{
EL ITINERARIO Y LAS COLECTAS DE SESSE Y MOCIÑO EN MEXICO
}

\author{
por Rogers McVAUGH ${ }^{1}$
}

En el siglo xviII, antes de la fundación de Chicago, Dallas y San Francisco, se realizó la exploración botánica de la vasta región de Nueva España. La Expedición Real de Botánica de Carlos Tercero fue una empresa grande. El personal de la Expedición incluyó cuatro o cinco botánicos y zoólogos, dos dibujantes y varios ayudantes. Los científicos viajaron millares de leguas en México mismo, en América Central, en las Indias Occidentales y a lo largo de la costa Pacífica de los Estados Unidos. Los dibujantes pintaron más de 1500 "Icones", o sea dibujos de plantas y animales en colores naturales. Los botánicos prepararon ejemplares para el herbario, de más de 2500 especies de plantas. Después de la iniciación de la exploración de México, en el año 1787, se extendió por más de diez años el trabajo en el campo.

La Expedición regresó a España en el año de 1803, con todos sus manuscritos, dibujos y plantas secas. No habían perdido nada, ni por naufragio, ni por contratiempo. El Director, don Martín de Sessé y Lacasta, y su colaborador botánico, el mexicano José Mariano Mociño, seguramente tenían la esperanza de ver publicados sus datos en la forma de una Flora Mexicana, o sea algo comparable a la famosa Flora peruviana et chilensis de Ruiz y Pavón, ya publicada en España. Desgraciadamente para las ambiciones de Sessé y Mociño, amenazó a España en aquella época el poder de Napoleón. El gobierno en Madrid no tenía ni interés ni dinero para apoyar la publicación de una Flora de Nueva España. Antes de la publicación de algunas partes importantes de sus trabajos, murió tanto Sessé como Mociño, y nunca se publicó, ni nunca se publicará, la flora completa de Nueva España. No obstante, la Expedición Real Botánica aumentó mucho nuestro conocimiento de las plantas de América Tropical. Durante varios años he dedicado una buena parte de mi tiempo a un estudio histórico de los trabajos de la Expedición, pero hoy quisiera restringirme a un aspecto algo especializado del trabajo, o sea un sumario de dos viajes en México de los exploradores.

Por lo general no se conoce que, con base en ejemplares botánicos recogidos por los científicos de la Expedición Real, han sido descritas cerca de dos mil especies de plantas americanas. Mil especies aproximadamente se describieron desde el año 1887 al de 1894, en las floras póstumas de Sessé y Mociño publicadas en México, a saber, las Plantae Novae Hispaniae, y la Flora Mexicana.

1 Universidad de Michigan, Ann Arbor E.U.A, 
Muchas de las supuestas especies nuevas, como hoy sabemos, ya habían sido descubiertas y denominadas por otros botánicos en el siglo transcurrido pero sin embargo hay algunas especies nuevas indudables de Sessé y Mociño que no se han descubierto en tiempos modernos.

Además de las especies publicadas en las floras mexicanas en 1887 y después, casi mil especies más se publicaron en Europa por otros sabios. Muchas personas tuvieron interés en los dibujos mexicanos, y también en algunos ejemplares duplicados, distribuidos a varios herbarios por el botánico Pavón entre 1815 y 1825. Cientos de plantas de México y de las Antillas Mayores, hoy día muy bien conocidas, recibieron nombres científicos por primera vez al encontrarse entre las colecciones de Sessé y Mociño. Así por ejemplo, botánicos suizos, franceses e ingleses, desde el año de 1813, estudiaron y describieron las especies nuevas. Por causa de estas numerosas especies, basadas en las colecciones de la Expedición Real, tiene mucha importancia hoy la ubicación precisa de cualquier localidad por donde viajaba la Expedición.

Muchos botánicos modernos han dejado de considerar las especies nuevas publicadas por Sessé y Mociño en las Plantae Novae Hispaniae y en la Flora Mexicana, porque no conocen íntimamente la geografía de Nueva España del siglo dieciocho, y tampoco pueden localizar las áreas mencionadas en las floras póstumas. Por ejemplo se cita varias veces en las floras una localidad que se llama Ixtla, como también otro lugar que se llama Puente de Ixtla. Ni la una ni la otra se encuentra en los mapas modernos ordinarios de un Atlas, y a pesar de la semejanza de los nombres, los lugares no están muy cercanos el uno al otro. Puente de Ixtla es del Estado de Morelos, camino de Acapulco, mientras que la otra Ixtla se encuentra cerca de Querétaro, como se revela por estudio detallado de los textos.

Como otro ejemplo, podemos mencionar la localidad Ahualulco que se cita más de 50 veces en la Flora Mexicana, sin mencionarse nunca la región ni tampoco otros lugares vecinos. El inglés T. A. Sprague (Kew Bull. 1926), al discutir los viajes mexicanos de Sessé y Mociño, supuso que se refería a la ciudad de Ahualulco en el Estado de Jalisco. Estudios nuevos del texto de la Flora Mexicana indican otra probabilidad. A algunas plantas de Ahualulco, por ejemplo, se dan el nombre específico "tabascensis" o "ocoapensis". Además, el nombre Ahualulco muchas veces se asocia con el del lugar "Acayuca", que no es de Jalisco. Las especies de Ahualulco por lo visto son naturales de los trópicos húmedos, pertenecientes a los géneros Piper, Epidendrum, Melastoma, etcétera. El lugar Ahualulco de Sessé y Mociño no se ha encontrado en ningún mapa, pero es probable que estuviera localizado en la tierra caliente del Estado de Tabasco, donde viajaba Mociño en el año de 1794. 
Con esta introducción larga, casi no necesito decir que se pueden identificar casi todas las localidades mexicanas mencionadas por Sessé y Mociño, y que se pueden seguir con confianza los itinerarios de los exploradores botánicos. Las fuentes principales de datos son: primero, las dos floras arriba mencionadas, segundo, una publicación muy valiosa del Dr. H. W. Rickett, intitulada "The Royal Botanical Expedition to New Spain" (Chronica Botanica vol. 11, 1947), y tercero, los archives del Instituto Botánico de Madrid y del Archivo General de la Nación, México, D. F., donde se encuentran todavía muchos documentos contemporáneos de la Expedición Real de Botánica.

La exploración botánica en el Valle de México se inició en el mes de octubre de 1787. Se colectaron plantas de varias localidades, como Tacubaya y San Angel, que se encuentran actualmente dentro de la zona urbana. Los botánicos visitaron también el monasterio viejo de los Padres Descalzos Carmelitanos, en los "montibus frigidissimis" del Desierto de los Leones.

Más tarde se alejaron los expedicionarios algo más de la capital, visitando al "Sacromonte" de Amecameca, Xochitlán, Yecapixtla, y probablemente al mismo tiempo Cuernavaca. Estos viajes preliminares los han llamado "La Primera Excursión".

En el verano del año 1789 se realizó la "Segunda Excursión", o sea el viaje a Chilpancingo y Acapulco. Pasaron varios meses en la vecindad de Mazatlán, Guerrera; localidades de colecciones son Chilapa, Ayahualtempa, Zitlala y Acahuizotla. Al Director Sessé en esta excursión le acompañó el botánico Castillo, a quien debemos el mayor número de las descripciones de las plantas nuevas que se descubrieron. Durante el mismo verano Mociño estudió en la Ciudad de México. donde participaba en el curso de botánica que enseñaba Cervantes. La expedición probablemente regresó a México en diciembre, pasando antes quince días en el puerto de Acapulco, y otros pocos días en Cuernavaca.

En mayo de 1790 salió de México la "Tercera Excursión". Viajaron lentamente por Querétaro, Guanajuato y Morelia, en aquel tiempo llamada Valladolid. Al llegar a la tierra caliente cerca de Apatzingán, probablemente en octubre, la expedición se detuvo durante unas semanas. Muchas plantas se encontraban en buenas condiciones para los estudios botánicos, y la región entre Apatzingán y Colima era la más productiva del viaje. Parece que la Expedición llegó a Colima en enero o febrero del año de 1791, y pasó entonces al este del Volcán de Colima, dirigiéndose hacia Sayula y Guadalajara. En esta ciudad descansaron durante dos o tres meses, arreglando sus colecciones, y preparándose para la continuación del viaje. Desde Guadalajara, el 22 de junio de 1791, expidió Sessé al Virrey, para su envío a España, varios especímenes, manuscritos y di- 
bujos. Es probable que los manuscritos, que consistían de dos tomos "en folio", eran los manuscritos originales de las Plantae Novae Hispaniae, copiados y concluidos por Mociño después de llegar a Guadalajara. Es muy interesante, pero naturalmente no concluyente, que en las Plantae Novae Hispaniae se describen plantas de las primeras tres "Excursiones", pero no se menciona ninguna localidad más allá de Guadalajara.

Desde Guadalajara, probablemente en el mes de julio de 1791, se dirigió la Expedición hacia Tepic. Se citan en la Flora Mexicana pocas colecciones de Tequila, de Jalisco, de Tepic, de Acaponeta, y de Sinaloa. Sessé, probablemente en las primeras semanas del año de 1792, regresó a México, En julio y agosto, acompañado por Castillo, exploró el Estado de México, subiendo a la zona alpina del Nevado de Toluca, y colectando mucho en el distrito de Temascaltepec. En el otoño del mismo año, Sessé y Castillo visitaron la región minera al norte de Pachuca, Hidalgo, y probablemente también la tierra caliente entre Pachuca y Papantla, Estado de Veracruz. Quedaron los botánicos dos meses en Veracruz y Puebla, antes de volverse a México.

Habiendo vuelto a México Sessé, Mociño, en el mes de febrero de 1792, se juntó en San Blas, Nayarit, con otra expedición española, y llegó finalmente a Nutka, en la costa de Columbia Británica, donde quedó durante más de un año.

Las exploraciones botánicas de los años siguientes se conocen por medio de localidades citadas en la Flora Mexicana (pero no mencionadas en las Plantae Novae Hispaniae), y por medio de la Flora de Guatemala en manuscrito que existe en Madrid. Se registran en dicha Flora más de 500 especies, pero muy pocas descripciones son completas. Aproximadamente 15 especies de Guatemala y Nicaragua se mencionan en la Flora Mexicana (están copiadas de la flora inédita de Guatemala), pero otras 500 especies colectadas por Mociño permanecen casi desconocidas.

En el año 1793 se concentró la exploración botánica en la vertiente atlántica, sobre todo en Veracruz e Hidalgo. Mociño visitó Oaxaca, regresó a Córdoba, y después, para estudiar las erupciones del Volcán de San Andrés de Tuxtla, subió dos veces a la cima del volcán. Sessé seguía trabajando en la vecindad de Córdoba y de Orizaba hasta mediados del mes de octubre, y después visitó la región de Puebla.

En 1794 repitió Mociño su viaje del año pasado, pasando desde Veracruz a San Andrés Tuxtla, y probablemente esta vez continuó a Tabasco.

En el año siguiente, 1795, inició Sessé su viaje a Cuba donde permaneció casi un año, antes de irse a Puerto Rico. Desde Puerto Rico regresó a La Habana en junio de 1797, y a México en mayo de 1798. Mientras tanto, Mociño, 
con el dibujante Cerda, había salido de México, con destino a "Guatemala", en junio de 1795. Su viaje a Guatemala resultó muy lento; trabajaron varios meses en el Estado de Oaxaca, especialmente cerca de Tehuantepec. Llegaron a la tierra alta de Chiapas en junio de 1796, como un año después de su salida de México, y continuaron por otros seis meses, es decir, hasta el mes de diciembre, antes de llegar a la ciudad de Guatemala. El año siguiente, 1797, llegaron en su viaje hasta la ciudad de León de Nicaragua, de donde iniciaron el regreso a México en 1798. Mociño llegó a México en febrero de 1799. Como se menciona arriba, la mayor parte de las especies de plantas descubiertas por Mociño a lo largo del camino a Nicaragua permanecen inéditas.

En conclusión, quisiera recordarles a ustedes la situación con que nos confrontamos. En el mundo entero existen hoy alrededor de 20000 plantas secas colectadas por Sessé y Mociño y los demás científicos de la Expedición Real de Carlos Tercero. Hay unas cuantas en casi todos los herbarios grandes de Europa, y algunos cientos o miles en ciertas instituciones. No obstante hay un problema serio; casi ningún espécimen de herbario lleva datos geográficos, y ordinariamente no es posible determinar el lugar de origen de este o aquel ejemplar. Hay que recordar que la mitad de la colección entera, más o menos, se colectó en el Valle de México. Sin embargo, hay ejemplares individuales de Columbia Británica, de Alta California, de Cuba y Puerto Rico, y de los países de América Central hasta Costa Rica. Ahora, felizmente, se conocen la mayor parte de las localidades de Sessé y Mociño, y tengo la esperanza de publicarlas próximamente, con lo cual para los botánicos en el futuro, habrá menos dificultades en la localización de las especies nuevas de dicha colección. 


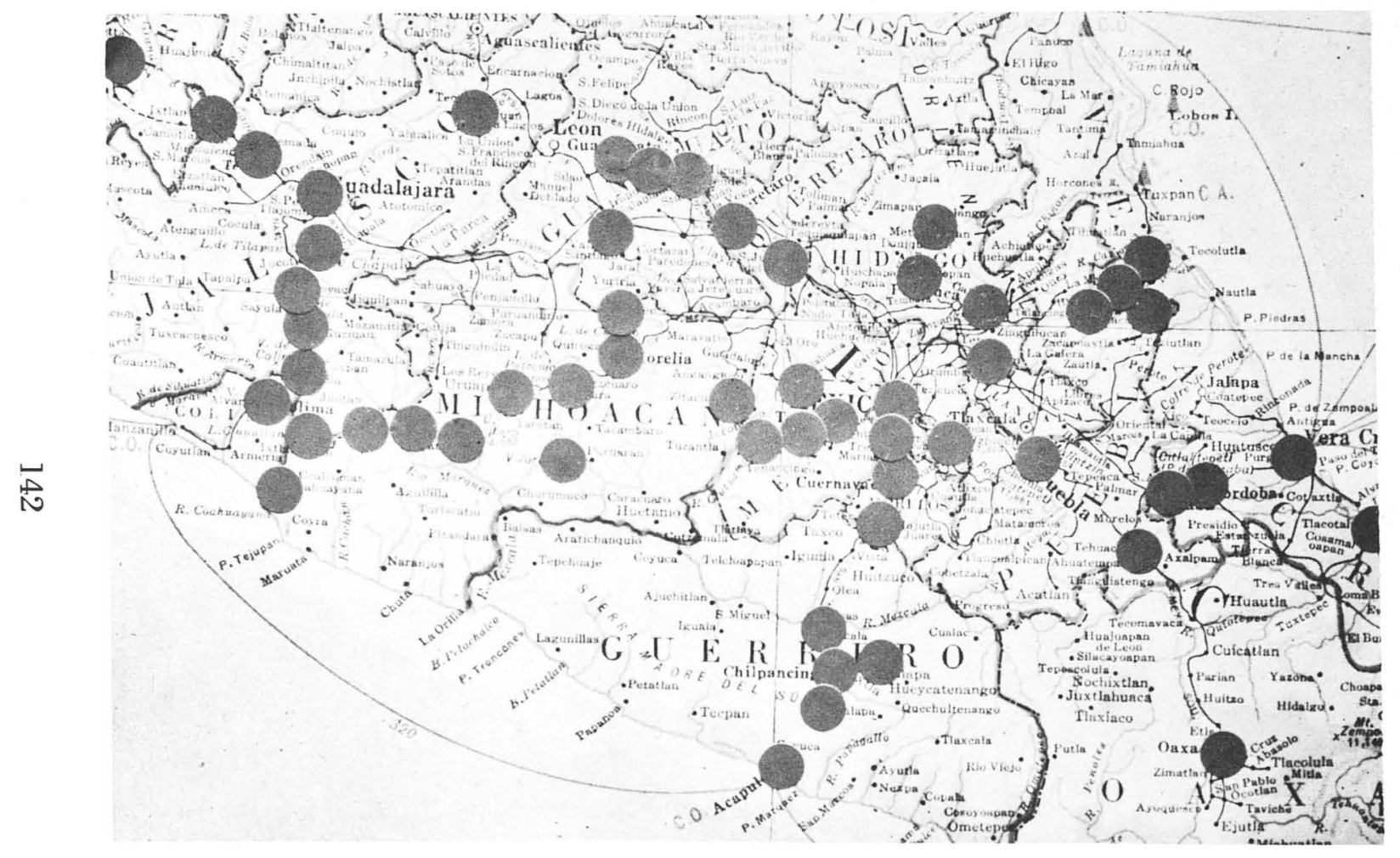

Fig. 1. Mapa de las exploraciones en la parte central de México, de la Expedición Botánica, 1787-1794. No se incluyen localidades de Nayarit ni de Sinaloa (1791-1792), ni tampoco las de las costas del sur de Veracruz y Tabasco (1793-1794). 